\title{
Rolling Stock: Library and Information Services for Gypsies and Travellers
}

\author{
KERRY WELLER \\ Oxford University Library Services, Oxford, United Kingdom
}

\begin{abstract}
Gypsies and Travellers have lived in Britain for over 500 years and yet the country's 'original and oldest ethnic minority' (Pateman 2004, 42) remains the least tolerated by the majority. This paper provides a brief cultural analysis based on the Gypsy Traveller way of life and how current policies and service provision create barriers to this culture and tradition. Library and information service requirements are identified in relation to specific needs, based on the issues
\end{abstract}

that directly affect this minority group. An examination of current policies and service provision will also identify existing barriers to enabling access to information. Proposals are made for providing library and information services appropriate to this minority community, in order to break down these barriers, enable access to information pertinent to their needs and tackle the issues that contribute to the social exclusion of the Gypsy Traveller community in Britain.

\section{A note on terminology}

A cultural analysis of this minority community will indicate that there are many separate and distinctive groups within the Traveller population of Great Britain who each have their own individual cultural heritage and traditions. However, the policies and provisions in place affect each of these communities in a number of similar ways and, therefore, improvements to information services provision and recommendations for appropriate library services are made for these groups as a whole. For the purposes of this paper, the term Gypsy Traveller will be applied to refer to these collective communities.

\section{Introduction}

'All the evidence shows that Travellers and Gypsies are some of the most vulnerable and marginalised ethnic minority groups in Britain. 'No Travellers' signs in pubs and shops can still be seen today, and councils no longer have a statutory duty to provide sites for Gypsy and Traveller families, spending small fortunes each year evicting them, instead. Gypsy and Traveller children are taunted and bullied in school, local residents are openly hostile to them, and scare stories in the media fuel prejudice and make racist attitudes acceptable.' (Commission for Racial Equality 2004, 2)

Gypsies and Travellers have lived in Britain for over 500 years and yet, it would appear, that as Britain's 'original and oldest ethnic minority' (Pateman 2004, 42) they remain the least tolerated by the majority. The recent Stonewall report Profiles of Prejudice (2003), also cited by Pateman, states that of the $64 \%$ of adults they surveyed, who can name a minority group that they feel 'less positive' towards, nearly 14 million adults (35\%) cited Gypsies and Travellers over and above other minority groups.

The discrimination suffered by this minority community has affected all aspects of their way of life from housing provision to health and education, on a local and national policy-making level. Of the estimated 300,000 Gypsies and Trav-

This paper was originally written in May 2004 as part of the coursework requirements for the 'Information Services Management' postgraduate degree course offered by the School of Information Management, London Metropolitan University and was later submitted to Libri's 'Best Student Paper' competition. The paper was partly re-edited in August 2005 for publication.

Kerry Weller is the Reader Services Librarian at the English Faculty Library, University of Oxford, St. Cross Building, Manor Road, Oxford, OX1 3UQ. E-mail: kerry.weller@efl.ox.ac.uk 
ellers living in Britain, 200,000 are living in settled housing due to a steadily decreasing lack of alternatives (Crawley 2004) and the nomadic lifestyle, inherent to the very nature of their culture, is under significant threat. If Gypsies and Travellers are to receive the level of welfare and support that should be available to every British citizen, and have the knowledge and ability to combat the social exclusion that they are so frequently subjected to, then access to relevant information and advice is essential. The public library service as 'a focal point for the provision of information services in the community... [has] an important role to play in helping combat social exclusion' (Department for Culture Media and Sport 1999, 7) and, therefore, is well placed to support the development of an informed and empowered Gypsy Traveller community.

The identification of the Gypsy Traveller community's specific information needs is essential to the success of any planned service. These can be identified, to some extent, through an appreciation of the cultural heritage and traditions of the Gypsy Traveller community and how these can often conflict with the established cultural practices of the mainstream settled population, resulting in barriers to social inclusion. Therefore, the following overview of the main issues affecting Gypsy Travellers involving accommodation, access to welfare, community and educational services will help to identify the information needs of the community and how the library service can assist with breaking down the barriers to social inclusion through increased access to information. Proposals for the provision of library services to the Gypsy Traveller community are then made, based on the needs identified.

\section{The Gypsies and Travellers of Britain}

\section{Population}

It is estimated that there are 300,000 Gypsies and Travellers living in Britain, a community slightly larger than the 280,000 strong Bangladeshi population (Crawley 2004). Within the Gypsy Traveller community there are a diversity of groups, each with their own culture, heritage and traditions. Kenrick and Clark (1999) identify five traditional travelling groups in Britain: the Romany Gypsies, Irish Travellers, Scottish Travellers, the Roma (from Europe) and the Kalé of Wales. Romany Gypsies were identified in law as being a racial group in 1988, and Irish Travellers received the same legal status in England and Wales in 2000 (Commission for Racial Equality 2004). Additional groups include Occupational Travellers such as the Travelling Showpeople, Circus and Boat Dweller communities (including Bargee, Sea and River Travellers). To these older travelling communities should be added the New Travellers, or 'New Age' Travellers as they are sometimes called.

Despite some groups within the Gypsy Traveller community having been identified in law as distinct ethnic groups, these are not included in the official UK Census and, therefore, accurate information on the size of the population is difficult to ascertain (Crawley 2004; Kenrick and Clark 1999; Morris and Clements 1999). The only official statistics are collected by the Office of the Deputy Prime Minister in its twice-yearly 'Gypsy Count'. The latest figures, released in July 2004, estimate that there are 9,627 families living in England either on authorised, unauthorised or private encampments. However, this count does not include those families of Gypsy Traveller heritage who are currently living in settled housing, either on a permanent or temporary basis. It is thought that a further 200,000 of the population live in housing (Kenrick and Clark 1999). This lack of accurate data has implications for any recommendations for improvements to library service provision. As Crawley $(2004,8)$ states:

\footnotetext{
The absence of official national figures on the size of the Traveller and Gypsy population is replicated by a lack of systematic ethnic data collection across key areas of service provision and employment. Because Travelling communities are often not included as a category in ethnic monitoring schemes of local authorities and statutory agencies, planning service delivery at local levels (such as housing, social services, health) does not take account of their needs'.
}

Therefore, the use of community profiling techniques, such as those outlined by Beal (1985), may not be appropriate in determining levels of library service provision required for Gypsy Traveller communities. Particularly as many Gypsies and Travellers may be unwilling to provide information relating to their ethnic origin for fear of exclusion and prejudice from the surrounding community. However, Local Authorities, Travel- 
ler Education Services (TES) and the National Association of Health Workers with Travellers (NAHWT) can provide links to the Gypsy Traveller community.

\section{Gypsy Travellers and social exclusion}

The Gypsy Traveller community has been consistently described as 'the most excluded group in society' (Traveller Law Reform Coalition 2003) and its children 'the group most at risk in the education system' (Ofsted 1999, 7). Many members of this community have 'deep-rooted fears about identifying their ethnicity' (Crawley 2004, 58 ), concerned over racist reprisals from the surrounding population, resulting in inadequate service pro-vision due to the isolation of the community and lack of sufficient data to service providers. This causes immediate problems for any library planning service provision for Gypsy Traveller communities within their local area through community profiling techniques. However, with the assistance of other agencies, such as the Traveller Education Service, service provision can be planned for and strategies put in place to tackle the barriers to social inclusion that Gypsy Travellers face. In their report on social inclusion from 2000, the Library \& Information Commission (LIC) goes so far as to state that 'Libraries epitomise inclusion in their values and activities; and by their presence in local communities ... Libraries are the essence of inclusion' (LIC 2000). Libraries, therefore, are well placed to address the specific information needs of the Gypsy Traveller community and, according to the LIC, are 'essential' in combating the kind of exclusion faced by Gypsy Travellers on a daily basis.

This atmosphere of exclusion has been fuelled by misconceptions of the majority (or host) community concerning Gypsy Travellers and their nomadic lifestyle. Their self reliance and independence from the established cultural practices of the settled population have been perceived as a rejection of assimilation and lack of willingness to conform. It can be argued, therefore, that the concept of cultural pluralism has yet to fully embrace the Gypsy Traveller community. This has been further underlined by recent Government policy, which has resulted in an assimilation of the Gypsy Traveller community into the settled population through the enforced surrender of the nomadic lifestyle and with it a large element of their cultural heritage.

\section{Government policies and service provision in the UK: their impact on the Gypsy Traveller community}

As one of the most socially excluded groups in British society, the Gypsy Traveller community is most in need of improved services provision. However, Government policies have exacerbated the problems facing Gypsy Travellers, creating barriers to social inclusion, thereby creating a need for information which could improve the difficult situation that many groups within this community are experiencing; information that could be made accessible through the local library service.

\section{Planning policy and its impact on the 'nomadic' lifestyle}

The main social unit of the Gypsy Traveller community is the extended family. Family groups are predominantly self-employed and seasonal employment has often been cited as a factor in the migration patterns of these groups. With the loss of many traditional encampments and roadside stopping places due to extensive building and redevelopment after the Second World War, accommodation for caravans and trailers became increasingly difficult to find.

The 1968 Caravan Sites Act sought to ensure that a network of stopping places and sites be situated throughout England and Wales by placing a legal obligation on Local Authorities to ensure that some site provision was allocated in every borough. However, these obligations were not often enforced. Many authorities feared the "honeypot" effect that such site provision was thought to encourage, resulting in an influx of travelling groups to the area (Crawley 2004; Kenrick and Clark 1999). Councils feared unpopularity with local residents more than prosecution for failing to uphold the law, and groups were often forced to travel hundreds of miles in order to find legal stopping places. This has resulted in poor access to consistent service provision in terms of education, healthcare, and access to community information.

In 1994 the introduction of the Criminal Justice and Public Order Act repealed the statutory duty of Local Authorities to provide site accommoda- 
tion for Gypsy Traveller groups. Brought about in reaction to the growing public concern over the rise in 'New Age' Travellers, unauthorised campsites and the costs to the taxpayer of providing Local Authority sites, the Act sought to ensure that Gypsy Travellers received the same treatment as the majority population in terms of responsibility for their accommodation, thus placing the onus on the Travelling community to find and purchase suitable land and then apply for planning permission. However, the Traveller Law Reform Coalition (TLRC) estimates that 'over $90 \%$ of planning applications are refused as opposed to $20 \%$ for the sedentary community' (2003). Morris and Clement $(1999,6)$ observe that:

\footnotetext{
'the argument that Gypsies should be the same as everyone else simply means that they should fit in with the needs, wishes, and values of the settled majority, and never vice-versa. This policy gives no recognition to the fact that it is settled people who are privileged under the planning system, in that they rarely have to endure any contact with it.'
}

This change in Government policy has only exacerbated the site provision problem. As Hawes and Perez state the nuisance was identified as illegal stopping and the remedy appeared to be the removal of the duty which ensured continued site provision' $(1995,1)$. A process of enforced assimilation has seemingly begun to take place whereby the Gypsy Traveller community have little choice but to remain settled in order to ensure they abide by the law. This settled existence has also affected the seasonal migration patterns of groups, resulting in loss of earnings and an increasing dependence on welfare and benefits. Families fear that moving on will result in the loss of their existing 'pitch' thus rendering them homeless, or forced to camp illegally and face eviction or the threat of prosecution, as the provision of transit sites is very limited in many areas.

However, not all groups travel all the time. Whilst migration patterns appear to be two-fold, self induced in the search for employment or enforced through local hostility (Crawley 2004), many groups remain settled for some years in the same location, for example in housing or Local Authority or privately owned sites. Opportunities exist therefore for local library services to engage with this static community through outreach programmes and services specifically provided for the Gypsy Traveller community. The formation of homework clubs to support Gypsy Traveller pupils in primary or secondary education or story time sessions for younger children will enable the creation of relationships between the library service and the Gypsy Traveller community through which further information needs could be identified.

Despite living on authorised sites, these families are not at an advantage by any means. Residents of sites do not have the same legal rights as residents of other non-Gypsy caravan sites and can be evicted with 28 days notice, even if they have lived there for 20 years or more. New policies often do not cover these authorised sites. Crawley (2004) cites the example of the new Disability Facilities Grant, which does not extend to the residents of Traveller designated sites. Often these sites are located close to hazardous or poor environments, for example next to sewage farms, railway lines or landfill sites; out of site of the local settled community, isolated from extended family groups and with poor access to local amenities and services. These poor living conditions and loss of culture and tradition have had a negative impact on the health of the community.

\section{Access to health, welfare and community services}

The NAHWT (2004) cite three factors which have directly resulted in an inequality of health for the Gypsy Traveller community: lack of safe stopping places and 'inadequate site provision', 'poor access to health care and limited continuity of care' and 'discrimination and prejudice'. At least two of these factors can be attributed to the changes in policy relating to site provision. Groups unable to find permanent accommodation or legal stopping places may have to travel extensively in search of a place to stay, and scheduled hospital appointments are difficult to keep. The inability for some groups to provide a permanent address can exclude them from registration with doctors' surgeries and so many groups are forced to use the Accident and Emergency departments of local hospitals for basic treatment.

Poor literacy levels and the requirements made by some welfare and community services for the completion of complicated forms have also created barriers to access. Again library service provision for the Gypsy Traveller community may be able to assist with the improvement of literacy levels 
amongst the adult population. Bhopal cites the case of adult literacy classes offered by a local primary school to the parents of Gypsy Traveller children attending the school which had an empowering effect on the mothers attending these sessions, enabling them to have 'greater control' $(2004,59)$ over the schools admissions process as they were able to complete forms themselves, rather than rely on the local TES teacher to complete paperwork on their behalf. The introduction of story time sessions provided by the local library service for Gypsy Traveller parents and children may have a similar effect, whereby adults will improve their literacy skills enabling them not only to read to their children themselves, but also providing them with the ability to overcome barriers to inclusion created by complicated bureaucracy and administrative procedures, seemingly pervasive in the healthcare and educational systems in Britain.

Whilst access to educational and healthcare services is available to all citizens under the requirements of law, as Perez and Hawes (1995) argue, the definitions that underpin legislation relating to Gypsy Travellers, in particular the 1968 Act, have further excluded some groups within this community, such as Showpeople, from local services others would take for granted. Their ineligibility to live within an authorised site has excluded them from the facilities this residential status may afford, amongst which may be included the public library service. Hawes and Perez observe that it is 'easy to see that rejection or exclusion from the right to a pitch makes every difference to the possibility of being able to avail oneself of the other [local] services' $(1995,139)$. However, the education system has sought to achieve some consistency of service provision for the children of Gypsy Traveller communities. It is within this educational framework that library and information services may be able to increase the level and quality of provision to this minority community.

\section{Gypsy Traveller pupils and the education system}

In its report Raising the attainment of minority ethnic pupils Ofsted identified Gypsy Traveller pupils as the group most at risk in the education system' $(1999,7)$. This has been reaffirmed by the 2003 Department for Education and Skills (DfES) report Aiming High which concludes that many
Gypsy Traveller pupils are 'at the greatest risk of underachievement' $(2003,3)$, identifying 'poor access and lack of opportunity to learn, rather than any learning difficulty' $(2003,6)$ as the main cause. Despite a statutory obligation on the part of parents to ensure that their children receive suitable full time education, pupils' experiences are often fragmented and inconsistent due to their mobility, albeit for many groups, their enforced mobility. Instances of bullying from fellow pupils and a lack of understanding on the part of the school to Traveller culture has also lessened the quality of educational experiences for Gypsy Traveller pupils (DfES 2003).

Unlike other service providers however, the educational system does have some provisions in place to compliment these nomadic lifestyles. Many families have their children registered at a 'base' school which will keep a place open for that child whilst the family is away travelling, granting the pupil authorised absence, for example, due to their trade (e.g. moving to different showgrounds during the fair season) or for traditional gatherings such as the Appleby Horse Fair (DfES 2003). Many Traveller families, particularly those who follow traditional circuits every year (Travelling Showpeople, for example) are highly organised in the education of their children, ensuring a consistent learning experience either through regular school attendance or through school-based distance learning whereby pupils are given work to complete based on the curriculum which can then be returned to the school either during or at the end of the travelling season (DfES 2003). As the British Educational Communications and Technology Agency (BECTA) state, 'to gain a good education it is not necessary to remain in one place but it is necessary to have a positive attitude' (BECTA 2000).

However, whilst levels of attendance in primary education are increasing, the numbers of pupils attending secondary and tertiary education remain low, as many families do not see the relevance of the curriculum to their way of life. BECTA (2000) report that 'most travellers prefer to work for themselves, so they are more interested in skills than bits of paper ... they want to learn, but only if what they are learning is relevant to them'. In addition, expectations of study support and access to resources are not high due to low levels of literacy and educational expecta- 
tions on the part of their parents. This situation could, potentially, increase the risk of 'educational and social exclusion' (DfES 2003, 9) for these pupils.

The TES has a critical role to play in ensuring the consistency and quality of education received by Gypsy Traveller pupils and seeks to safeguard educational opportunities for all Traveller children. The TES provides many valuable services such as assisting with advice on school admissions, assessing and advising on any additional support that Traveller pupils may require and advising on the nature of this support. They provide support teaching from specialist teachers and training sessions to other school and local agency staff who come in to contact with Gypsy Traveller pupils and offer learning and educational resources reflecting the Gypsy Traveller culture. Joint working initiatives have also been employed between other groups working with this community to improve upon the educational experiences of these pupils, e.g. the Advisory Council for the Education of Romany and other Travellers (ACERT), the Gypsy Council, The Literacy Trust and the National Association of Teachers of Travellers (NATT). The partnership of Educational Advice for Travellers, the Travellers Aid Trust and Friends, Families and Travellers (FFT), for example, has led to the production of a series of ten books aimed at the 3-7 year age range, featuring Tess the Traveller (Earle and Heulin 2002), specifically for and about New Travellers. Access to a wide range of relevant resources could potentially increase literacy levels amongst Gypsy Traveller pupils, increasing confidence and self esteem as well as introducing non-Gypsy Traveller pupils to alternative lifestyles (Literacy Trust 2003).

Furthermore, access to relevant information and advice for all members of the Gypsy Traveller community is essential in order to ensure fair and equal treatment in a socially inclusive society. Train et al. state that 'it is the right of every citizen to be included in society, a notion which is paralleled in the public library service that the public library should be equally available to all' (2000, 484). To facilitate this move towards a socially inclusive society, one in which cultural pluralism is celebrated, improvements to library services and resources for Gypsy Travellers will be needed in order to support the development of an informed and empowered Travelling community.

\section{Proposals for providing library and information services for the Gypsy Traveller community}

The following are proposals for improved information services for the Gypsy Traveller community. These proposals will be made in conjunction with those information needs identified in previous sections. Whilst improved access to information on accommodation and healthcare will be touched upon, the main focus of these proposals will be on joint working initiatives between local libraries and the Traveller Education Service to tackle the serious problem of literacy levels within the community, assistance for children attending local schools, and how the implementation of these proposals may assist with the flow of information transfer within the community.

Pateman (2004) outlines a six-point plan for libraries wishing to tackle social exclusion, based on the strategic approach outlined in the 2001 report Libraries, Museums, Galleries and Archives for All (Department for Culture, Media and Sport). Included amongst these points are: the need to assess current practice, develop strategic objectives and prioritise resources, develop services and train staff in order to provide these services. A similar plan has been adopted by the library service in the Windsor and Maidenhead Unitary Authority area. Working closely in conjunction with the Thames Valley Consortium TES, the library service at Maidenhead has implemented a pilot programme to provide library services to Travellers on a nearby residential site. The following six proposals, whilst taking account of the six-point plan, will also take account of good practice based on this and other projects in the UK.

\section{Establish contact with relevant local agencies}

Establish contact with relevant local agencies (e.g. TES, NAHWT, local council housing unit) to ascertain information relating to Gypsy Traveller groups within the area in order to create a community profile. Cross agency collaboration will be necessary for any library service seeking to determine information on the local Gypsy Traveller community in order to assess the level of service provision required, particularly as traditional means of community profiling may be difficult to undertake due to inaccurate data and the po- 
tential reticence of members of the community, particularly those living in local housing in the library's catchment area, to disclose their ethnicity for fear of persecution.

\section{Establish links with the local Gypsy Traveller community}

Establish links with the local Gypsy Traveller community in order to market the proposed new service and to assess their perceived information needs. The reticence identified by the Essex library service (Smith 2004) of these close-knit and independent communities to seek external help from non-Gypsy Travellers should also be taken in to account and some sensitivity will be required when proposing new services. Any approach to the community in the first instance would be best served through a mediating agency, such as the local TES, who can advise the Travelling community of the intended new service and provide personal introductions to selected library staff. In the case of Maidenhead library, staff were first given training sessions by the Thames Valley Consortium TES on aspects of Traveller culture in order to prepare staff for their initial visits, thus creating a dialogue between the two groups and a sympathetic environment in which to develop the service. Selected members of Maidenhead library staff were then introduced to the community through a series of on-site storytelling sessions involving mothers and children to introduce them to materials and resources that the library service could provide and to work towards improving literacy levels amongst the adult residents by encouraging them to join in with these storytelling sessions.

\section{Review current provision and resources}

Review current provision and resources in conjunction with both the TES, library staff and with the local Traveller community itself. Establish the potential adaptability of the current mobile library service in order to minimise budgetary considerations, by using transportation resources already available, and to ensure consistency of long-term service provision. Essex library service (Smith 2004) also identified that the library being housed in a mobile trailer proved less intimidating for many users. Whilst in the short term visits will need to be specially scheduled in order to introduce the service, the long-term aim should be for these residential sites to become part of the regular route. However, if the cost of taking the mobile library to the site would exceed the budget for the project, then smaller scale visits could be arranged. For example, at Maidenhead public library, two members of staff take boxes of resources to the site travelling by car. The library sessions then take place in the living room of one of the Traveller's trailers. This has created a friendly and informal atmosphere in which to introduce the service and develop relationships with the residents on site. The central library should also be promoted should new members wish to take advantage of the wider range of resources and services on offer. Access policies may need to be reviewed in order to accommodate such provision, for example requests for documentation relating to a permanent address may not be appropriate in some cases and form filling may cause unnecessary anxiety. At Maidenhead library, all the books borrowed on site are recorded as on loan to the 'Travellers Storytime' ticket, and, therefore, no proof of address or other documentation is required from individuals.

If budgetary restrictions are a factor in the acquisition of relevant stock, resources from the local TES could be borrowed. The low literacy levels of some members of the community should also be taken in to account and audiovisual materials should be provided for both adults and children. The award-winning [1] Essex library service for Travellers provides highly pictorial books relating to Traveller history and heritage for those members of the community unable to read in order that they too may benefit from the service. A more inclusive collection development strategy should be devised providing, for example, book titles specifically written about Gypsy Traveller children - like Jimmy's Idea (Swatridge 2001) and Shaun's Wellies (Norfolk TES 1995) - and books in the Romany language. Maidenhead library service have reported that these types of books have been particularly popular with the children on site, as it is the first time they have come into contact with books depicting children with lifestyles similar to their own. Stock relating to Traveller culture should also be available in the main library building to ensure provision for those members of the community living in local housing and 
also to provide the non-Gypsy Traveller community with resources and information that will reflect the diversity of their local community and address misconceptions and prejudice that may exist regarding the Gypsy Traveller community.

\section{Implement a strategy to tackle issues of social exclusion}

Implement a strategy to tackle issues of social exclusion, if one is not already in place and ensure that all staff are made aware of the strategy, the need for the new service and identify staff that can provide specific services to the Gypsy Traveller community. The formulation of a strategy will increase awareness amongst staff of social exclusion issues, enable them to become more informed when promoting or discussing the service to existing library members and will further promote issues of social inclusion to the wider community. Establishing outreach services as part of an overall strategic plan, promoting issues relating to social inclusion, lifelong learning and the improvement of adult and child literacy levels may also provide a justification for long term service provision when library services are subjected to Unitary Authority review. It may also be necessary to market the scheme to library staff in order to allay any concerns or tackle any hostility from staff towards the project. Existing staff skills can be utilised in order to develop the concept of this new service being an extension of existing service provision, not an addition. For example, children's librarians can work in close conjunction with mothers to develop regular reading/story time sessions. Homework clubs and study support sessions can be set up using existing library resources to aid pupils currently attending primary and secondary education.

\section{Assess the information needs of the community}

Whilst the main agenda for this service should be a recreational as well as educational one, the earlier sections of this report have demonstrated that certain issues directly affect the Gypsy Traveller community in a negative and often distressing way. With the implementation of the People's Network, [2] and the rapid improvements and developments in information and communication technologies, widening access to valuable sources that may otherwise have remained isolated from the community will be easier to achieve. In particular, access to information relating to planning legislation and legal advice, local surgeries and health workers providing treatment to Travellers in transit as well as settled groups, schemes to improve reading and writing skills for semi-literate adults and vocational skills training for young adults can be provided either through the Internet or through promotional literature.

Introductory sessions for adults and children in the use of e-mail and the Internet could improve the information transfer process within the local Gypsy Traveller community, enabling access to the community on a national level as well as improving communication links to extended family and the wider local community. For example, using existing resources such as the FFT Web site, 'Cyber Pilots' [3] which encourages the development of communications between children of different Gypsy Traveller communities could be used to facilitate learning, develop IT skills and improve communication links to the wider Gypsy Traveller community. Children can be registered by their parents and guardians and are able to access content and information aimed directly at enhancing their educational experiences and improving their ICT skills. The Web site could also be used as an educational resource for non-Gypsy Traveller children with which they can learn more about the experiences of children living different lifestyles to their own.

\section{Monitor and evaluate the service}

Monitor and evaluate the service, to ensure consistency of service provision and to promote the service to the wider professional community. Best practice and guidance from existing projects should be monitored and experiences shared with other agencies and library services, both locally and regionally, in order to form a pool of knowledge which can then be disseminated on a national scale to other agencies and professional bodies such as the NATT and the Chartered Institute of Library and Information Professionals.

\section{Conclusion}

These proposals have been targeted towards library services piloting new outreach programmes 
to Traveller communities that have, in the past, been excluded from current service provision. The identification of the information needs pertinent to this community and an understanding of the very real difficulties faced on a daily basis by Gypsy Travellers should be the foundation of any planned library service provision for the Gypsy Traveller community. It should be the long-term aim of any outreach service, however, to become another part of the existing service, not a special addition. This does not suggest that mobile services in operation should be retracted after a period of time in order to assimilate the community into the main body of the public library readership. Sites located in isolated rural areas and the custom of the extended family engaged in activities as a whole unit (due, in part, to the anxiety felt by parents when their children are away from the protection of the community), indicates that the use of the central library is not always a practical or viable option. However, long term planning of a successful service should encourage members of both the Gypsy Traveller and nonGypsy Traveller local community to consider themselves as provided for and part of a socially inclusive but culturally diverse, culturally aware society in which the library service plays an informing and empowering role.

\section{Notes}

1. Winner of the 2004 CILIP/ LiS Libraries Change Lives Award. http://www.cilip.org.uk/aboutcilip/ medalsandawards/LibrariesChangeLives/lclafin04. htm [viewed October 18, 2005]

2. 'a project to connect all public libraries to the internet' (Resource: The Council for Museums, Archives and Libraries 2003). URL: http://www.mla. gov.uk/documents/pnleaflet.pdf [viewed October 18, 2005]

3. URL: http://www.gypsy-traveller.org/ cyberpilots/ [viewed October 18, 2005]

\section{References}

Beal, Christina. 1985. Community profiling for librarians. CRUS Occasional Paper No. 12. Sheffield: Centre for Research in User Studies.

Bhopal, Kalwant. 2004. Gypsy Travellers and Education: Changing needs and changing perceptions. British Journal of Educational Studies 52(1): 47-64.

British Educational Communications and Technology Agency. 2000. Implementing the whole curriculum:
Traveller education in the UK. URL: http://www. becta.org.uk/teachers / teachers.cfm?section=1_3_4\& id $=816$ [viewed October 18, 2005].

Commission for Racial Equality. 2004. Gypsies and Travellers: A strategy for the CRE, 2004-2007. London: CRE. URL: http://www.cre.gov.uk/policy/gypsies_ and_travellers.html [viewed October 18, 2005].

Crawley, Heaven. 2004. Moving Forward: the provision of accommodation for Travellers and Gypsies. London: Institute for Public Policy Research.

Department for Education and Skills. 2003. Aiming High: Raising the Achievement of Gypsy Traveller Pupils. Nottingham: DfES.

Department for Culture, Media and Sport. 1999. Libraries for All: Social Inclusion in Public Libraries. London: DCMS. URL: http:/ /www.culture.gov.uk/ NR/rdonlyres/42818901-0EA3-4AE5-B1C2-1689ABC 069BD/0/Social_Inclusion_PLibraries.pdf [viewed October 18, 2005].

Department for Culture, Media and Sport. 2001. Libraries, Museums, Galleries and Archives for All: Cooperating Across the Sectors to Tackle Social Exclusion. London: DCMS. URL: http:/ /www.culture.gov.uk/ PDF/libraries_archives_for_all.pdf [viewed October 18, 2005]

Earle, Fiona \& Heulin, Ross. 2002. Tess the Traveller storybook series. Grantham: Educational Advice for Travellers in partnership with The Travellers Aid Trust \& Friends, Families and Travellers.

Hawes, Derek \& Perez, Barbara. 1995. The Gypsy and the State: The ethnic cleansing of British Society. Bristol: Policy Press.

Kenrick, Donald \& Clark, Colin. 1999. Moving On: The Gypsies and Travellers of Britain. Hatfield: University of Hertfordshire Press.

Library and Information Commission. 2000. Libraries: the essence of inclusion. URL: http://www.mla.gov. uk/information/legacy/lic_pubs/policyreports/ inclusion.html [viewed October 18, 2005].

Literacy Trust. 2003. Travellers and Literacy. URL: http:// www.literacytrust.org.uk/Database/travellers.html [viewed October 18, 2005].

Morris, Rachel \& Clements, Luke, ed. 1999. Gaining Ground: Law Reform for Gypsies and Travellers. Hatfield: University of Hertfordshire Press.

National Association of Health Workers with Travellers. 2004. Special Interest Group for Travellers: The National Association of Health Workers with Travellers Web page. URL: http://www.msfcphva.org/sigs/ sigtravellers.html (information provided by the Community Practitioners' and Health Visitors' Association) [viewed April 28, 2004].

Norfolk Traveller Education Service. 1995. Shaun's Wellies. Norwich: Norfolk Traveller Education Service.

Office for Standards in Education. 1999. Raising the attainment of minority ethnic pupils: school and LEA 
responses. London: OFSTED. URL: http://www. ofsted.gov.uk/publications/index.cfm?fuseaction= pubs.summary\&id=771 [viewed October 18, 2005].

Office of the Deputy Prime Minister. 2004. Count of gypsy families on $19^{\text {th }}$ July 2004: last five counts. London: ODPM. URL: http://www.odpm.gov.uk/ stellent/groups/odpm_housing/documents/ divisionhomepage/035471.hcsp [viewed October 18, 2005].

Pateman, John. 2004. Tackling exclusion: Gypsies and Travellers. Library and Information Update 3(3): 42-43

Smith, Laura. 2004. Words on Wheels. The Guardian, $5^{\text {th }}$ May. London: Guardian Newspaper Ltd.

Stonewall/Citizenship 21 Project. 2003. Profiles of Prejudice.

Swatridge, Sarah Mary. 2001. Jimmy's Idea. Wokingham: Thames Valley Consortium, Traveller Education Service.

Train, B., Dalton, P. \& Elkin, J. 2000. Embracing inclusion: the critical role of the library. Library Management. 21(9): 483-90.

Travellers Law Reform Coalition. Who are the travellers? URL: http://www.travellerslaw.org.uk/issues.htm [viewed October 18, 2005].

\section{Bibliography}

4 Nations Child Policy Network. 2003. Gypsy Traveller Pupils: Guidance and good practice for Schools and LEAs. URL: http://www.cpinfo.org.uk/features/ index.cfm?ccs $=2101 \& \mathrm{cs}=7780 \&$ highlight $=$ gypsies [viewed October 18, 2005].

Acton, Thomas. 1974. Gypsy politics and social change. London: Routledge \& Kegan Paul.

Advisory Council for the Education of Romany and other Travellers. 1993. The education of Gypsy and Traveller children: Action-research and co-ordination. Hatfield: University of Hertfordshire Press.

Baird, Rachel. 2004. We can't cope with huge gipsy [sic] invasion. Daily Express, $22^{\text {nd }}$ January.

Bhopal, Kalwant with Gundara, Jagdish, Jones, Crispin \& Owen, Charlie. 2000. Working Towards Inclusive Education: Aspects of Good Practice for Gypsy Traveller Children, Research Report No. 238. London: DfEE. URL: http:/ /www.dfes.gov.uk/research/data/ uploadfiles/RR238.doc [viewed October 18, 2005].

Carpenter, Julie \& Trohopoulos, Ioannis. 1998. Mobile Libraries and New Information services in Public Libraries: Issues Arising from the MOBILE Project. IFLA Journal 24(2): 97-101. URL: http://www.ifla. org/V/iflaj/2402abs.pdf [viewed October 18, 2005].

Commission for Racial Equality. 2004. Discrimination against Gypsies and Travellers is the last 'respectable' form of racism, says the CRE. In: CRE News Release, Friday $2^{\text {nd }}$ April. URL: http://www.cre.gov.uk/
Default.aspx.LocID-0hgnew01c.RefLocID-0hg00900 c001002.Lang-EN.htm [viewed October 18, 2005].

Council of Europe. Roma and Travellers. URL: http:// www.coe.int/T/DG3/RomaTravellers/Default_en. asp [viewed October 18, 2005].

Datta, Suman \& Simsova, Sylva. 1989. Cultural Diversity and Libraries: Today and Tomorrow. London: PNL Press.

Day, Peter \& Harris, Kevin. 1997. Down-to-Earth vision: Community Based IT Initiatives and Social Inclusion. London: IBM.

Gypsy Council, The. 2003. The Hub (Spring) URL: http://www.btinternet.com/ thegypsycouncil/ newsletter/hub/page2.doc [viewed October 18, 2005].

Harvey, Oliver. 2004. See EU on Saturday. The Sun, $26^{\text {th }}$ April. London: News Group Newspapers Ltd.

Liégeois, Jean-Pierre. 1999. School Provision for Ethnic Minorities: The Gypsy Paradigm. Hatfield: Gypsy Research Centre, University of Hertfordshire Press.

Nicholas, David 1996. Assessing Information Needs: Tools and Techniques London: Aslib.

Office of the Deputy Prime Minister. 2003. Count of gypsy caravans on $16^{\text {th }}$ July 2003: Last five counts. London: ODPM.

Office of the Deputy Prime Minister. 2003. The provision and condition of local authority/gypsy traveller sites in England. London: ODPM. URL: http://www. odpm.gov.uk/stellent/groups/odpm_housing/ documents/pdf/odpm_house_pdf_602542.pdf [viewed October 18, 2005].

Pateman, John. 2002. Cultural revolution. Library and Information Update 1(1): 42-43.

Pateman, John. 1999. The State, Communities and Public Libraries: their role in tackling social exclusion. Information for Social Change 9 (Summer). URL: http://libr.org/ISC/articles/9-exclusion.html [viewed October 18, 2005].

Pantry, Sheila, ed. 1999. Building community information networks. London: Library Association Publishing.

Sibley, David. 1981. Outsiders in urban society. Oxford: Basil Blackwell.

Taylor, Diane. 2003. Gypsy voices. The Guardian, $19^{\text {th }}$ August. London: Guardian Newspaper Ltd.

Townsend, Mark. 2003. A burning issue in the village. The Observer, $16^{\text {th }}$ November. London: Guardian Newspaper Ltd.

Vesey-Fitzgerald, Brian. 1973. Gypsies of Britain: An Introduction to their History. Revised Edition. Newton Abbott: David \& Charles.

\section{Editorial history:}

paper received 17 December 2005;

final version received 29 September 2005;

accepted 19 October 2005. 